\title{
Plantas medicinais usadas para a saúde bucal pela comunidade do bairro Santa Cruz, Chapada dos Guimarães, MT, Brasil ${ }^{1}$
}

\author{
Aneliza Meireles Borba ${ }^{2,4}$ e Miramy Macedo ${ }^{3}$
}

Recebido em 17/12/2004. Aceito em 20/04/2006

\begin{abstract}
RESUMO - (Plantas medicinais usadas para a saúde bucal pela comunidade do bairro Santa Cruz, Chapada dos Guimarães, MT, Brasil). Em Mato Grosso, populações tradicionais recorrem ao uso de espécies vegetais como alternativa terapêutica. Na cidade de Chapada dos Guimarães, o bairro Santa Cruz se destaca por abrigar famílias nascidas em áreas urbanas ou rurais que conservam esses conhecimentos transmitidos por gerações. Esta pesquisa tem como objetivo o levantamento das plantas medicinais utilizadas pela comunidade local, indicações terapêuticas, preparos e modos de uso visando a manutenção e recuperação da saúde bucal. Foram entrevistados 40 residentes, através de abordagem qualitativa, usando entrevista semi-estruturada. As espécies catalogadas foram depositadas para identificação no UFMT/Herbário Central. Foram citadas 87 espécies pertencentes a 48 famílias utilizadas na saúde bucal, encontradas no bioma Cerrado ou cultivadas nas residências. Conforme as afecções bucais citadas, as espécies utilizadas são: para erupção dentária: camomila (Matricaria chamomilla L.); candidíases, estomatites, gengivites e afta: açafrão (Crocus sativus L.); dor de dente: arnica-da-serra (Brickelia brasiliensis (Spreng.) Robinson). A folha foi a parte da planta mais usada e o chá, por decocção, modo de preparo mais comum. Pessoas idosas, líderes comunitários, parteiras e benzedeiras entrevistados apresentaram um maior conhecimento sobre o assunto. Constatou-se que a comunidade utiliza espécies vegetais, nativas do cerrado ou exóticas, com finalidade terapêutica para manutenção e recuperação da saúde bucal, sendo uma alternativa tradicional, econômica e atuante.
\end{abstract}

Palavras-chave: Etnobotânica, indicações terapêuticas, Cerrado, quintais

\begin{abstract}
Medicinal plants used for oral health in the Santa Cruz neighborhood, Chapada dos Guimarães, Mato Grosso State, Brazil). In the State of Mato Grosso, traditional populations turn to the use of many plant species as a therapeutic alternative. In the city of Chapada dos Guimarães, the Santa Cruz neighborhood is well known for harboring families from urban and rural communities who preserve this knowledge passed down through many generations. The objective of this research was to survey the medicinal plants used by the local community, therapeutic indications, preparation and use methods intended to maintain and recover oral health. Forty local residents were interviewed by a qualitative approach using semi-structured interviews. The cataloged species were filed for identification in the UFMT/Herbário Central. There were 87 species named as being used for oral health, pertaining to 48 families, found in the Cerrado biome or grown at home. The most frequently cited species for treating oral ailments were as follows: teeth eruption - "camomila" (Matricaria chamomilla L.); candidiases, stomatitis, gingivitis and canker sores - "açafrão" (Crocus sativus L.); tooth ache - "arnica-daserra" (Brickelia brasiliensis (Spreng.) Robinson). The most commonly used part of the plant was the leaf while tea, by decoction, was the most common method of preparation. Elderly people, community leaders, accoucheuses and medicine women had a greater knowledge of medicinal plant use. This shows that the community uses both native cerrado and exotic plant species therapeutically to maintain and recover oral health, as a traditional, economic and effective alternative.
\end{abstract}

Key words: Ethnobotany, therapeutic indications, cerrado, home garden

\section{Introdução}

Desde seus primórdios, o ser humano percebeu os efeitos curativos das plantas medicinais, notando que de alguma forma sob a qual o vegetal medicinal era administrado (pó, chá, banho e outros) proporcionava a recuperação da saúde do indivíduo (Matos 1999).
As plantas medicinais, utilizadas há milhares de anos, servem de base para estudos na produção de novos fármacos (Macedo et al. 2002). Estima-se que $80 \%$ da população no Terceiro Mundo faz uso de fitoterápicos, sendo que $85 \%$ destes possuem extratos de plantas medicinais (EMBRAPA 1994).

No Brasil, a utilização de plantas no tratamento de doenças apresenta fundamental influência das

1 Parte da Dissertação de Mestrado em Saúde e Ambiente, Área de Etnobotânica, Universidade Federal de Mato Grosso

2 Secretaria de Saúde do Estado de Mato Grosso

3 Universidade Federal de Mato Grosso, Instituto de Saúde Coletiva e Herbário Central, Programa de Pós-graduação

4 Autor para correspondência: Rua Los Angeles, 431, Jardim Califórnia, 78070-400 Cuiabá, MT, Brasil (anemb@terra.com.br) 
culturas indígena, africana e européia. A cultura brasileira sofreu sérias influências desta mistura de etnias, tanto no aspecto espiritual, como material, fundindo-se aos conhecimentos existentes no país.

A base da formação da medicina popular é hoje retomada pela medicina natural, que aproveita seu conhecimento prático dando-lhe, porém, um caráter científico na tentativa de restituir a saúde ao ser humano, de uma forma natural (De-La-Cruz-Mota \& Guarim Neto 1996; Rodrigues \& Carvalho 2001).

Atualmente, observa-se o ressurgimento da medicina natural, enfatizando as plantas medicinais para restabelecimento da saúde humana. Com este acontecimento, inúmeras terapias alternativas e naturais despontam para alimentar as necessidades de bem estar do ser humano.

Um dos fatores que contribui para a larga utilização de plantas para fins medicinais no Brasil é o grande número de espécies vegetais encontradas no país. Nos últimos anos, tem aumentado a aceitação da fitoterapia no Brasil, resultando em crescimento da produção industrial dos laboratórios. Observa-se também o surgimento de cultivos caseiros e de novos usuários, havendo necessidades de orientação à população.

Mato Grosso, localizado na região Centro-Oeste do país (Fig. 1), é o estado que possui a maior área de Cerrado com $422.125 \mathrm{~km}^{2}$ (Pereira et al. 1997). Este bioma representa uma das maiores riquezas naturais brasileiras em espécies vegetais, incluindo as de uso medicinal (Sano \& Almeida 1998). O Cerrado é rico em espécies medicinais, mas desconhecidas do ponto de vista científico e o extrativismo descontrolado vem reduzindo a diversidade de espécies vegetais desta região (Vieira \& Martins 1996).

Entretanto, por apresentar características favoráveis de solo, clima e posição geográfica, o Cerrado mato-grossense vem sendo utilizado nos últimos anos para a produção agropecuária. Com esse objetivo, a vegetação nativa está sendo transformada em áreas agrícolas o que, segundo Ribeiro \& Silva (1996), proporciona uma das principais vias de degradação da biodiversidade da região. Essas novas áreas agrícolas que surgem são resultado da substituição dos ecossistemas originais pelos agroecossistemas, causando grande impacto ao meio ambiente (Campanhola et al. 1997).

O Cerrado mato-grossense é um dos biomas brasileiros mais ameaçados, onde plantas medicinais nativas necessitam de conservação. Neste sentido há necessidade de eliminar-se a distância que separa a técnica e a pesquisa científica das tradições, costumes

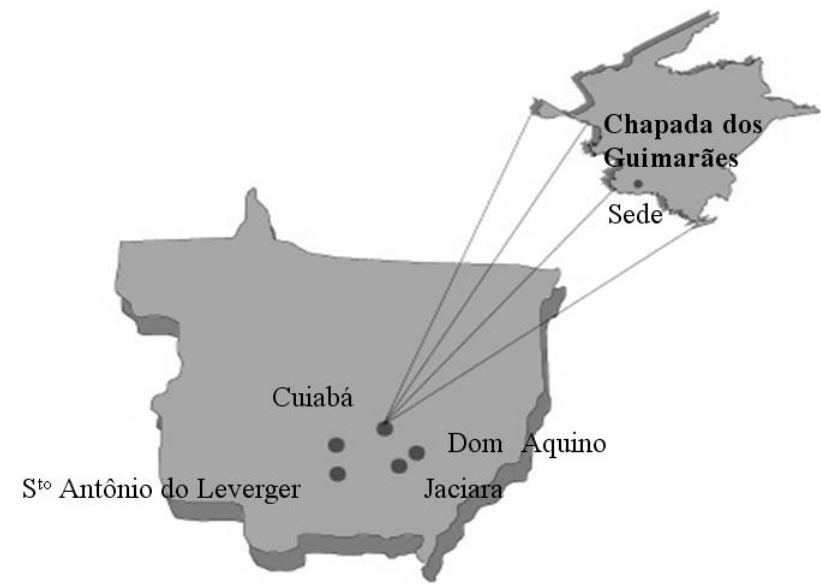

Figura 1. Localização do município de Chapada dos Guimarães, Mato Grosso, Brasil; entre as coordenadas geográficas $15^{\circ} 10^{\prime}-15^{\circ} 30^{\prime}$ latitude Sul e $55^{\circ} 40^{\prime}-56^{\circ} 00$ longitude Oeste (AP Consultoria, 2003).

e crenças populares. A partir do momento em que são analisados esses enfoques - aplicando-lhes critérios, métodos e objetivos - reduz-se esse distanciamento, dando aos conhecimentos populares uma comprovação científica e contribuindo para divulgar à população em geral conhecimentos úteis, antes apenas utilizados in loco, valorizando tanto a cultura quanto a ciência de um povo.

A odontologia, nos dias de hoje, tem como objetivo trabalhar com a saúde do indivíduo, sem esperar que as doenças bucais cheguem e consigam causar mutilações. Neste contexto, Walter et al. (1996) observam que a mãe é responsável por mais de $95 \%$ dos cuidados com a saúde do bebê, sendo o vetor responsável pelas transferências de educação, conhecimentos, hábitos e tradições culturais dos pais para a criança.

Pinto (1997) observa o quadro epidemiológico de saúde bucal no Brasil é o reflexo de algumas das principais características de nossa sociedade: a economia em crise prolongada, desigualdades salariais e sociais agudas, sistema educacional com prioridade na formação de nível superior; produção agrícola voltada para exportação, grande número de pessoas de baixa renda e em estado de pobreza relativa ou absoluta. $\mathrm{Na}$ área odontológica, levantamentos epidemiológicos mostram que no indivíduo a doença cárie tem um crescimento contínuo e impetuoso ao longo da vida, proporcionando a perda precoce dos dentes através da realização de inúmeras extrações, principal característica do quadro odontológico brasileiro na atualidade.

Oportunidades para o dentista trabalhar em comunidades vêm surgindo nos últimos tempos. No 
ano de 2000, o Ministro da Saúde anunciou a inclusão da saúde bucal no Programa de Saúde da Família (PSF) do governo federal, sendo este ato, um marco divisor da odontologia brasileira.

Revilla (2002) lembra que a OMS, na estratégia Saúde para todos no ano 2000, finalmente reconheceu a necessidade de incorporar à Saúde Pública os princípios, recursos e técnicas da Medicina Natural, pois além de aliviar as enfermidades de milhões de pessoas, é uma alternativa terapêutica praticamente sem custo.

O estudo do conhecimento e das conceituações desenvolvidas pela sociedade a respeito do mundo vegetal permite saber as indicações e o modo de uso das plantas medicinais. Desta forma, novos métodos terapêuticos têm a oportunidade de serem avaliados clinicamente em sua eficácia, podendo também ser aconselhados em procedimentos odontológicos.

Segundo Guarim Neto (1987), o conhecimento empírico sobre o tratamento de diferentes males que perturbam o homem deve ser conservado e nota-se que ele é geralmente evidenciado em conversas com as pessoas mais idosas que, por um motivo ou outro, carregam consigo essas preciosas informações e o seu registro é altamente necessário, tendo em vista que elas servem de subsídios para o conhecimento da flora nacional e, no caso específico, da flora mato-grossense. Amorozo (1996) acrescenta que a idade do informante, nesta categoria medicinal, apresenta uma forte relação positiva, acreditando que a aquisição do conhecimento neste domínio ocorra por toda a vida, dando oportunidade deste conhecimento ser absorvido por seus descendentes.

Segundo Ribeiro \& Silva (1996), na região CentroOeste desde o final da década de 70, vem ocorrendo mudanças na base principal de sua economia, pois a pecuária dependia da utilização da pastagem nativa. Com o incentivo governamental e adoção da mecanização, a vegetação nativa começou a dar lugar às monoculturas de espécies cultivadas apenas no período de chuvas como a soja, o milho, o arroz e o algodão, deixando o solo desnudo na época de seca. Conseqüentemente, estão ocorrendo mudanças do clima, escassez da flora e da fauna da região, afetando o modo de vida e a saúde dos seus habitantes. Através da diminuição do poder aquisitivo vem a desnutrição e o abandono da terra que antes trazia sustento o ano inteiro. Incentivar o cultivo e o uso de espécies nativas pode ser uma alternativa econômica para o aproveitamento sustentado da região.

Diante do exposto, esta pesquisa visa o levantamento das plantas medicinais utilizadas como terapia alternativa em relação à manutenção e recuperação da saúde bucal, seus preparos e modos de usos, conservados por moradores do bairro Santa Cruz, da cidade de Chapada dos Guimarães, no Estado de Mato Grosso.

A área de estudo está localizada no município de Chapada dos Guimarães (Fig. 1), Estado de Mato Grosso, que, conforme Ferreira (1997), está situado no Planalto Central do Brasil, entre as bacias hidrográficas do Rio Amazonas e Rio Paraguai.

\section{Material e métodos}

A escolha do campo de estudo foi baseada na observação de que, na região de Chapada dos Guimarães, o uso de plantas medicinais é antigo, sendo utilizadas por curandeiros, benzedeiras, raizeiros e parteiras - personalidades tradicionais conhecidas na região (Neves 1994).

Assim, o bairro Santa Cruz foi selecionado entre outros, por ser um dos primeiros bairros da cidade. A primeira etapa da pesquisa foi a realização de visita à área de estudo e consulta à Prefeitura Municipal, para requisição de dados sobre a cidade e do bairro a ser estudado, como também, para informar a intenção do trabalho.

$\mathrm{Na}$ escolha dos informantes foi levado em consideração que os domicílios a serem visitados fossem de pessoas residentes no lugar, possuidoras de sabedoria popular sobre o uso de plantas medicinais e capazes de usar e passar tais conhecimentos a outros indivíduos, transmitidos de geração a geração, através de relatos orais, fatos característicos em sociedades tradicionais.

Esta seleção foi efetuada através de dados obtidos em resposta a um questionário apresentado aos moradores e atendendo aos critérios propostos por Amorozo (1996) e Savastano \& Di Stasi (1996). Os itens observados foram: morar há mais de 15 anos no bairro Santa Cruz, estar na faixa etária acima de 20 anos, fazer uso ou ter conhecimento sobre o uso das plantas medicinais, ter adquirido este conhecimento de maneira informal, ter disponibilidade para participar da pesquisa.

Após a seleção, foi solicitada autorização de cada participante para divulgação dos resultados.

As coletas de dados junto aos informantes foram realizadas através da abordagem qualitativa, utilizando as técnicas de entrevista semi-estruturada e de observação. 
Para limitar o número de informantes e determinar o universo de plantas medicinais contido no conhecimento popular da comunidade, foi adotado procedimento adaptado ao conceito de curva espécieárea (ACIESP 1997). Assim, a cada entrevista foram registradas as citações de novas espécies, resultando em uma curva que foi estabilizada no momento em que deixaram de ser citadas espécies diferentes pelos informantes.

As coletas botânicas foram efetuadas durante as visitas aos quintais e ao cerrado no entorno da cidade, escolhendo-se as plantas ou partes destas, com mais representatividade, para preparo das exsicatas e identificação, preferindo plantas medicinais em fase de fertilidade, floridas ou frutificadas (Ming 1996; Macedo et al. 1998).

As espécies vegetais coletadas foram fotografadas e posteriormente depositadas no Herbário Central da Universidade Federal de Mato Grosso (UFMT/Herbário Central), onde se encontram devidamente identificadas.

\section{Resultados e discussão}

Entrevistou-se 40 pessoas entre 23 e 87 anos de idade, $60 \%$ maiores de 50 anos, estando a faixa de maior representatividade entre 70 a 79 anos (25\%) e a de menor representatividade entre 80 a 89 anos, com apenas $5 \%$. O sexo feminino foi predominante em relação ao sexo masculino, representado por $87 \%$ (Fig. 2).

Verifica-se que o conhecimento é adquirido ao longo do tempo. Os mais idosos da comunidade são, geralmente, os principais informantes. Em relação ao sexo, as mulheres possuem maior conhecimento do

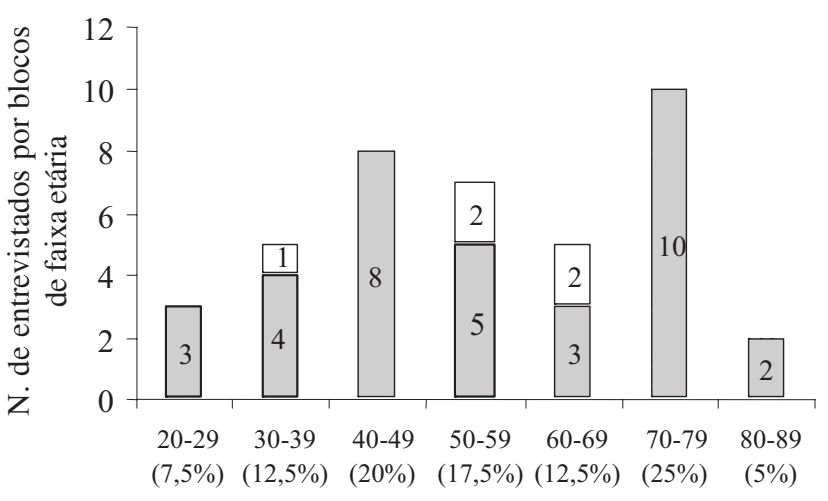

Faixa etária

Figura 2. Distribuição dos 40 informantes segundo a faixa etária e o sexo. ( $\square$ = sexo masculino; $\square=$ sexo feminino $)$. uso de plantas medicinais para problemas específicos do sexo feminino ou de crianças e também conhecem melhor os recursos vegetais relacionados a problemas domésticos, principalmente quando estes são encontrados próximos aos domicílios. Amorozo (1996), Macedo \& Pacheco (2001) e Viertler (2002) também colaboraram com a presente afirmativa.

Observou-se que do total dos 40 informantes, 21 eram casados, havendo quatro pessoas solteiras e 15 viúvas.

Constatou-se entre eles um alto índice de não escolarizados (45\%), e que apenas um deles possuía $3^{\circ}$ grau completo.

Verificou-se também que dos 40 entrevistados, 39 nasceram no Estado de Mato Grosso e apenas um em Minas Gerais. Entre os de Mato Grosso, 31 nasceram em Chapada dos Guimarães, sendo 16 provenientes da zona rural, que mudaram para a zona urbana.

Os informantes convivem no bairro em estudo há bastante tempo, tendo no mínimo 15 anos de residência e $30 \%$ deles já residem entre 20 a 29 anos no local. Registra-se o caso de uma moradora com 78 anos de idade que nunca morou fora deste bairro e de uma outra que reside no local há apenas cinco anos, apesar de trabalhar há mais de 15 anos junto àquela comunidade.

A religião é a Católica, crença muitas vezes herdada dos pais e seguida pelos filhos, às vezes por comodidade e obediência durante a infância e juventude, porém, com advento da maturidade, alguns deles mudaram de religião. Em seguida vem a Protestante (Igreja Evangélica e Igreja Universal), enquanto um informante afirmou ser seguidor de duas religiões ao mesmo tempo (espírita-católica) e outro não tem religião adotada.

As famílias do bairro são numerosas, tendo uma média de seis filhos cada, existindo alguns lares com 14 filhos.

As ocupações variaram desde o trabalho na roça, preparadores de garrafadas, parteiras, entre outras, sendo a ocupação do lar a mais freqüente $(37,5 \%)$.

Observou-se a importância e o respeito que a comunidade reserva a benzedores e parteiras, em relação aos usos alternativos de cura, registrando-se entre os informantes a presença de uma benzedeira e duas parteiras. Neste sentido, Amorozo (1996) enfatiza estes líderes possuem saber especializado, adquirido inexplicavelmente por nascimento ou 'dom divino', para ser usado em ocasiões especiais.

Registrou-se o número de plantas medicinais citadas por cada informante, verificando o número de 
inéditas indicada por cada um. Observou-se que as informações começaram a ser repetitivas nas últimas entrevistas, uma vez que, desde o $36^{\circ}$ até o $40^{\circ}$ entrevistado nenhuma citação nova foi acrescentada (Fig. 3), chegando-se a um total 130 espécies vegetais.

Entretanto, apenas 87 espécies (Tab. 1) tinham indicação para uso em saúde bucal e estão distribuídas em 48 famílias.

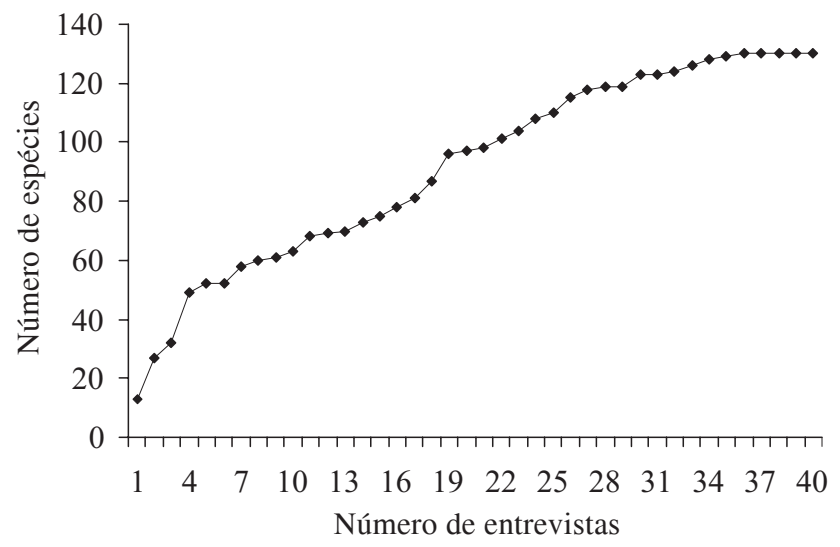

Figura 3. Freqüência acumulada das citações de novas espécies vegetais, por número de entrevistas.

Constatou-se que 50 espécies são de origem exótica e as demais 37, são de origem nativa.

Quanto ao hábito foram observadas 43 espécies herbáceas, uma herbáceo-arborescente, duas herbáceo-rasteiras, 15 árvores, 15 arbustos, oito subarbustos e três trepadeiras.

As espécies para uso medicinal caseiro foram encontradas nos quintais das residências, geralmente localizados nos fundos das casas e com dimensões variáveis, ou nas áreas remanescentes de Cerrado, nos arredores do bairro Santa Cruz. Algumas plantas, apesar de serem obtidas diretamente do ambiente sem nenhum cultivo (nativas), muitas vezes foram encontradas nos quintais, como ipê-roxo (Tabebuia heptaphylla Vell.), piquí (Caryocar brasiliense Camb.), capim-barba-de-bode (Bulbostylis capillaris (L.) Clarke), assa-peixe (Vernonia ferruginea Less.), caferana (Vernonia polyanthes Less.), fedegoso (Senna occidentalis (L.) Link.) e marcela (Achyrocline satureoides (Lam.) DC.), e outras, que geralmente precisam de cultivo por serem exóticas, conseguiram germinar espontaneamente nos quintais nos períodos de chuva, como por exemplo, a tanchagem (Plantago major L.).

A maioria das pessoas da comunidade usa plantas medicinais no seu cotidiano e aprendeu estes segredos com seus pais, parentes e amigos como afirmou uma informante: "Estou com 67 anos, fiz até o $4^{\circ}$ ano daquele tempo, mas sou curta da vista... Me criei no mato e tive oito filhos, quatro homens e quatro mulheres. Sou igual a índio, ando no mato e aprendo com os outros. Um fala uma coisa, o outro também... Aprendi as plantas com meu bisavô índio, minha sogra índia e minha mãe índia.” (A.S., 67 anos).

Silva (2001) observou nas pessoas vindas do interior para a periferia de Vitória, ES grandes vestígios da cultura de seus antepassados, quanto ao uso de plantas medicinais para doenças da boca, utilizando informações passadas de geração em geração.

Na comunidade do bairro Santa Cruz, a forma mais usada no preparo do medicamento caseiro foi o chá por decocto (55\% das espécies), seguido pelo chá por infusão ( $41 \%$ das espécies), maceração ( $22 \%$ das espécies) e sumo ( $8 \%$ das espécies), observando-se que uma espécie vegetal pode ter mais de uma maneira de preparo para sua utilização terapêutica. Além destas formas, foram citados no estudo, em menores proporções, preparos como: tintura, xarope, garrafada, pó, melado, torrado, in natura, queimada, cinza e amassado (Tab. 1). As partes das plantas mais usadas foram a folha (44\%), seguida da raiz $(16 \%)$, fruto $(8 \%)$, entrecasca $(7 \%)$, ramo $(6 \%)$, casca $(5 \%)$ e semente $(5 \%)$.

O uso acentuado da folha, também citado por Medeiros et al. (2004), mostra que os usuários procuram manter a integridade das espécies vegetais, retirando partes delas que possam ser repostas normalmente pelas próprias plantas, minimizando o seu risco de perda ou extinção. Entretanto, é notório o grande uso da raiz pela comunidade na confecção do remédio caseiro.

O conceito de saúde e doença está quase sempre relacionado à alegria de viver e à religiosidade, como na expressão: "com saúde fico alegre e acordo cedo e vou ouvir os hinos..." (M.J.S., 57 anos), ou a disposição do corpo nas tarefas diárias: "A gente com saúde o corpo quer acordar, comer e trabalhar... com doença a gente vê a diferença no corpo..." (L.S., 55 anos).

Os entrevistados acreditam no benefício e fazem uso de plantas medicinais e todos eles afirmaram que a primeira opção de medicamento para qualquer perturbação de saúde em geral seria procurar resolver com remédio caseiro, depois procurar o médico. Buscam o remédio, quase sempre em seus quintais ou no Cerrado. Resultado semelhante foi registrado no município de Santo Antônio do Leverger em Mato Grosso, por Amorozo (2002). 


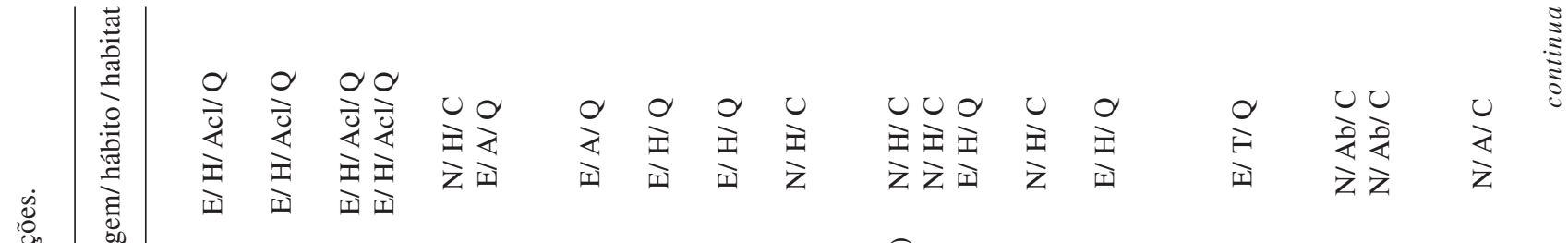

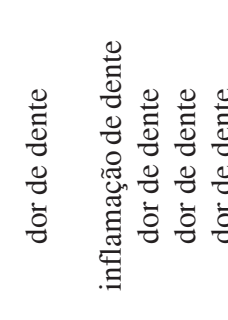

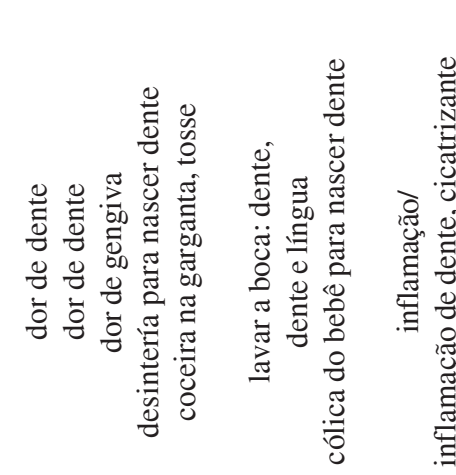
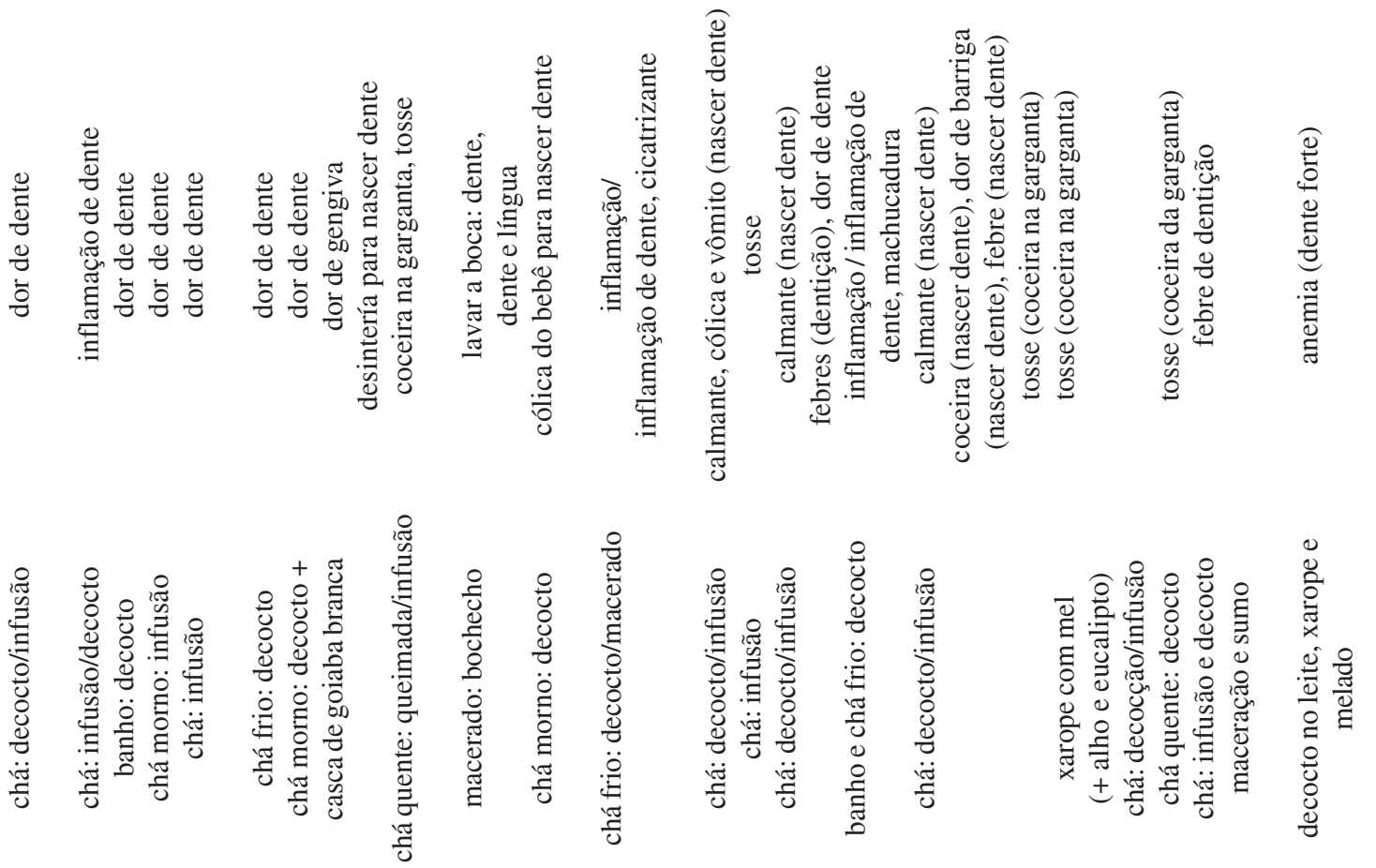

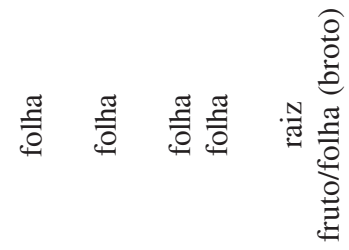

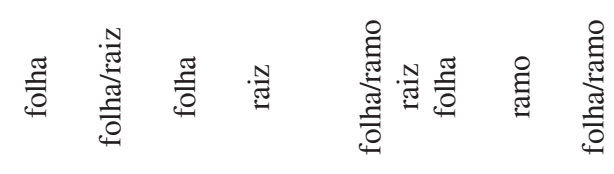

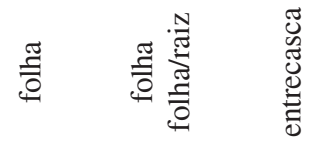<smiles>C[C@H]1C[C@H](C)[C@@H](C)[C@H]1C</smiles><smiles>CCCCC(C)C</smiles>

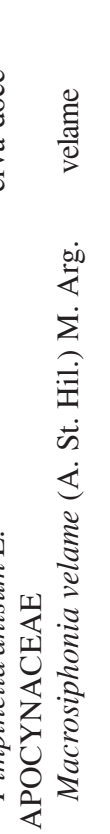

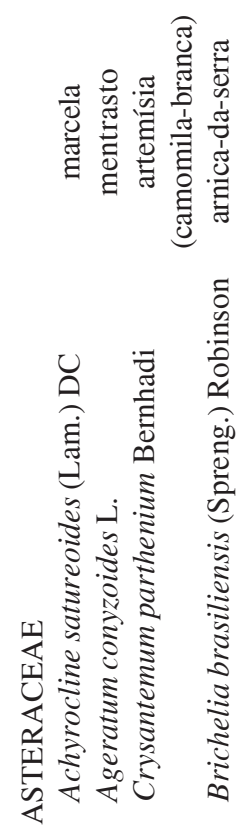<smiles>C1CCCCC1</smiles>

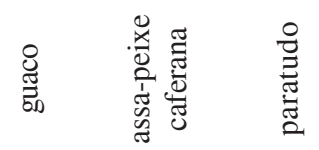

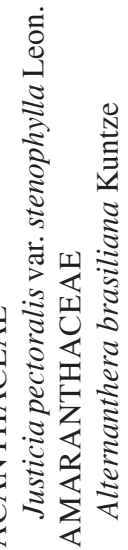

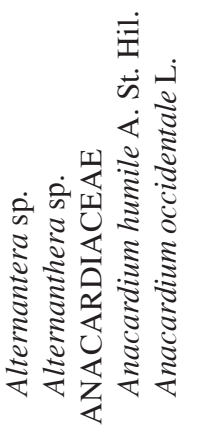
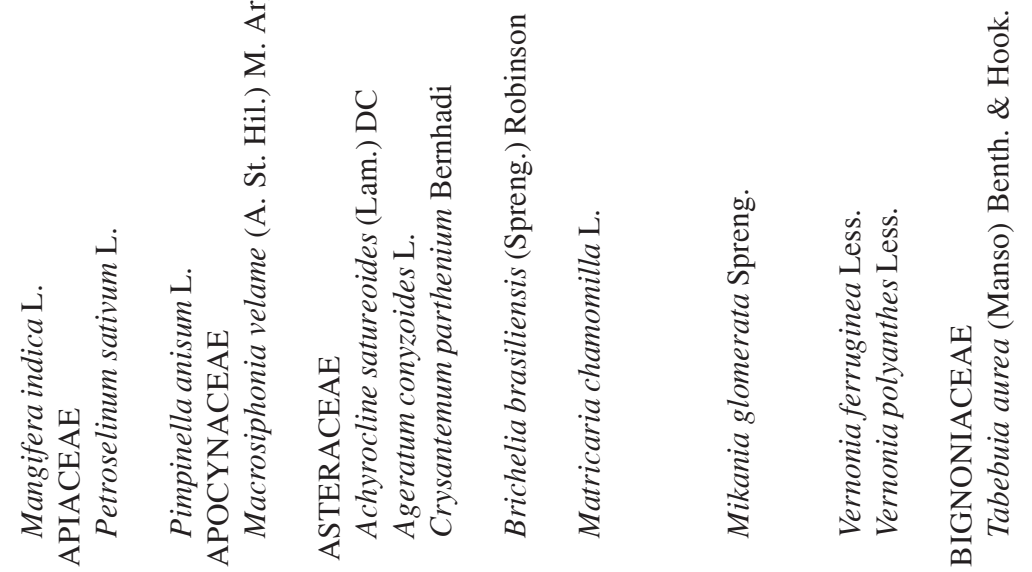


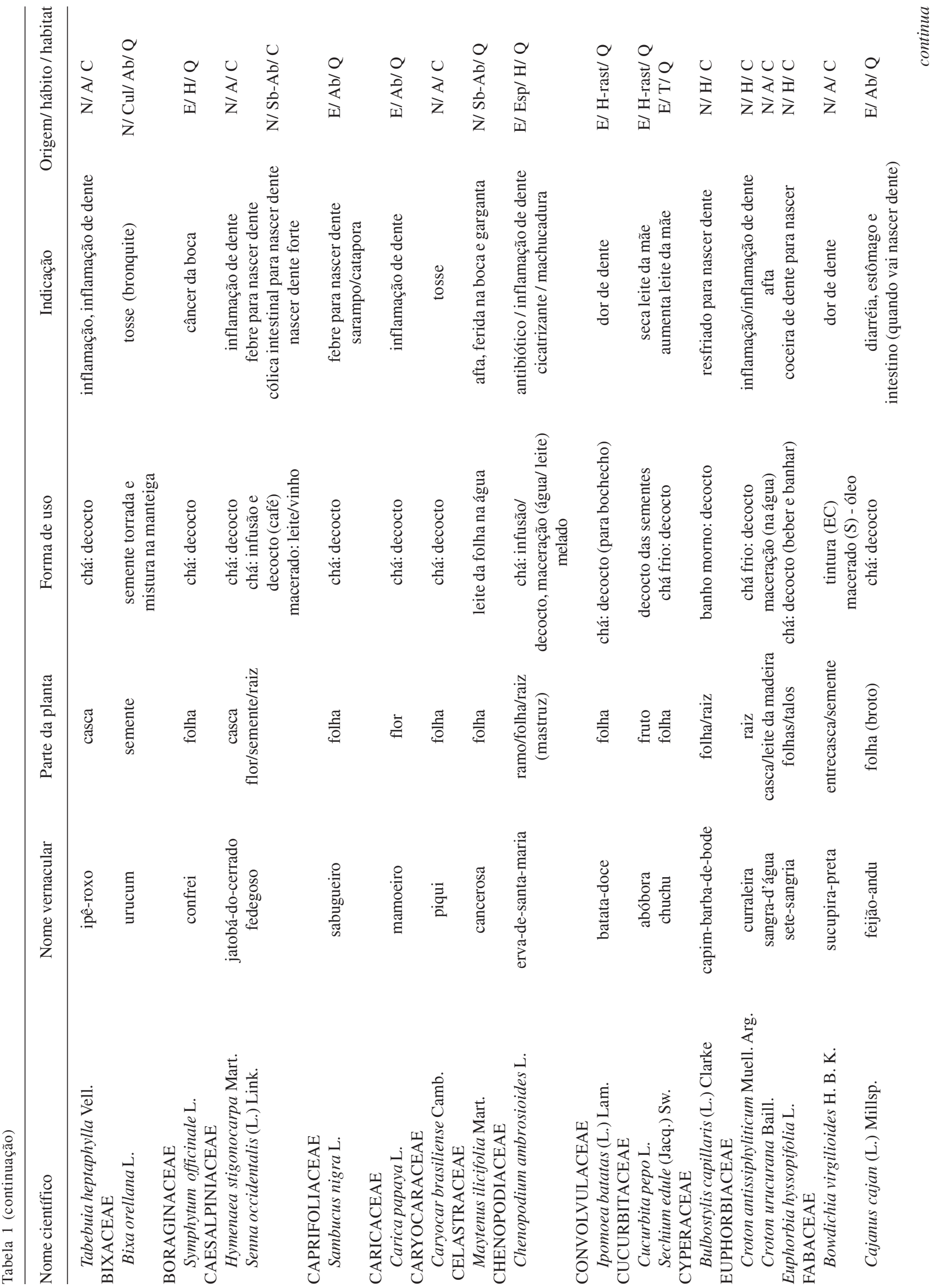




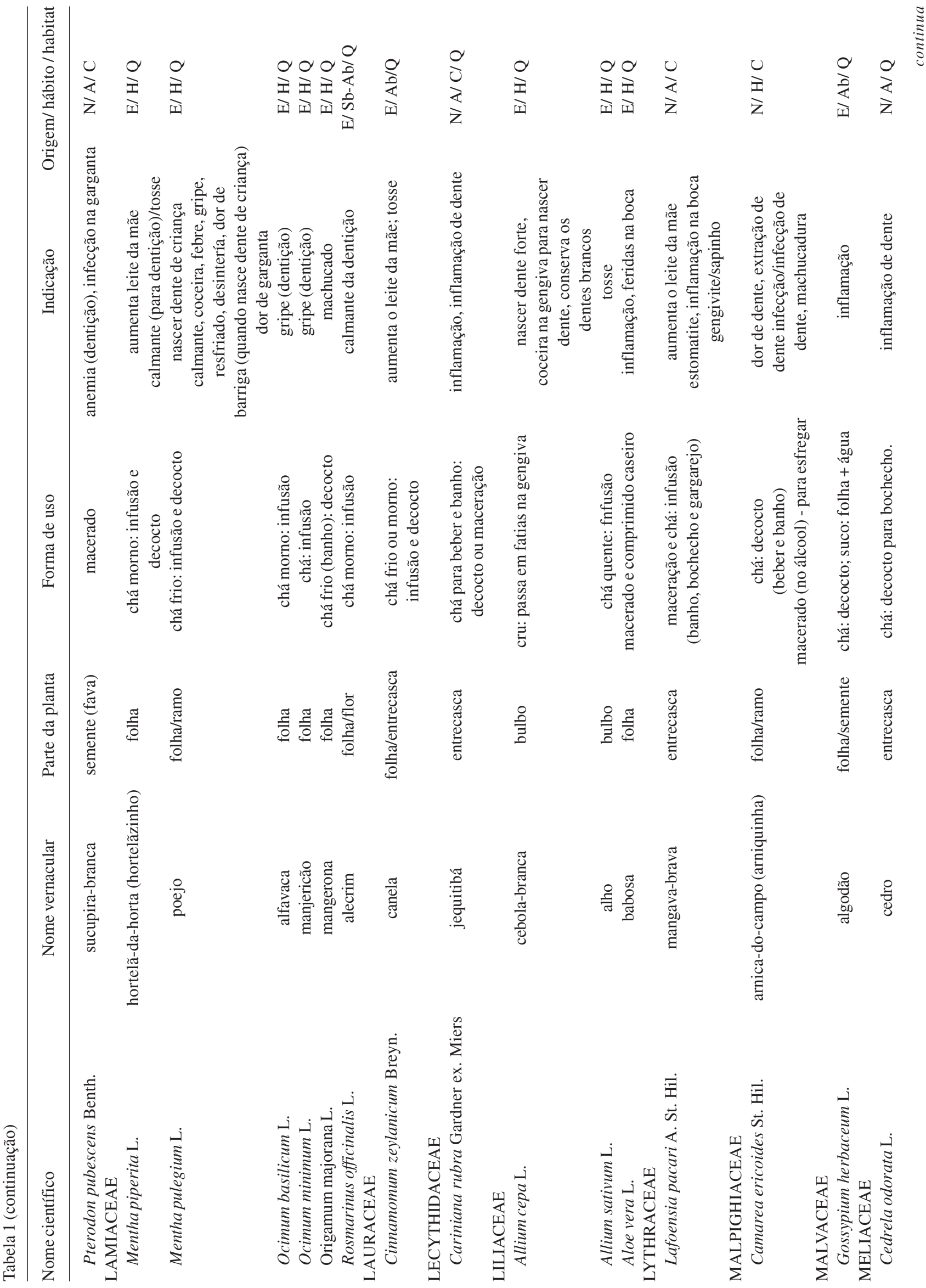




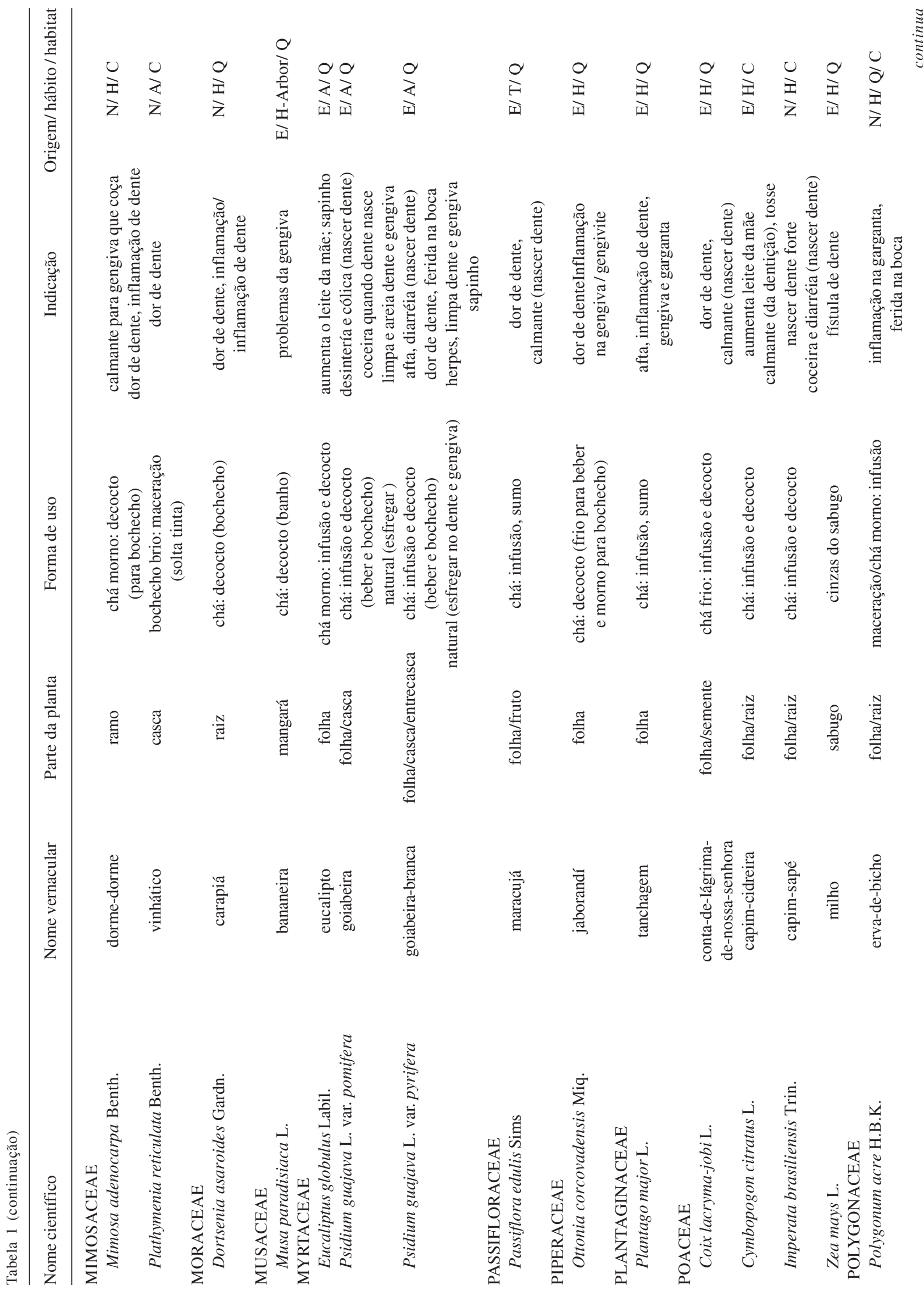




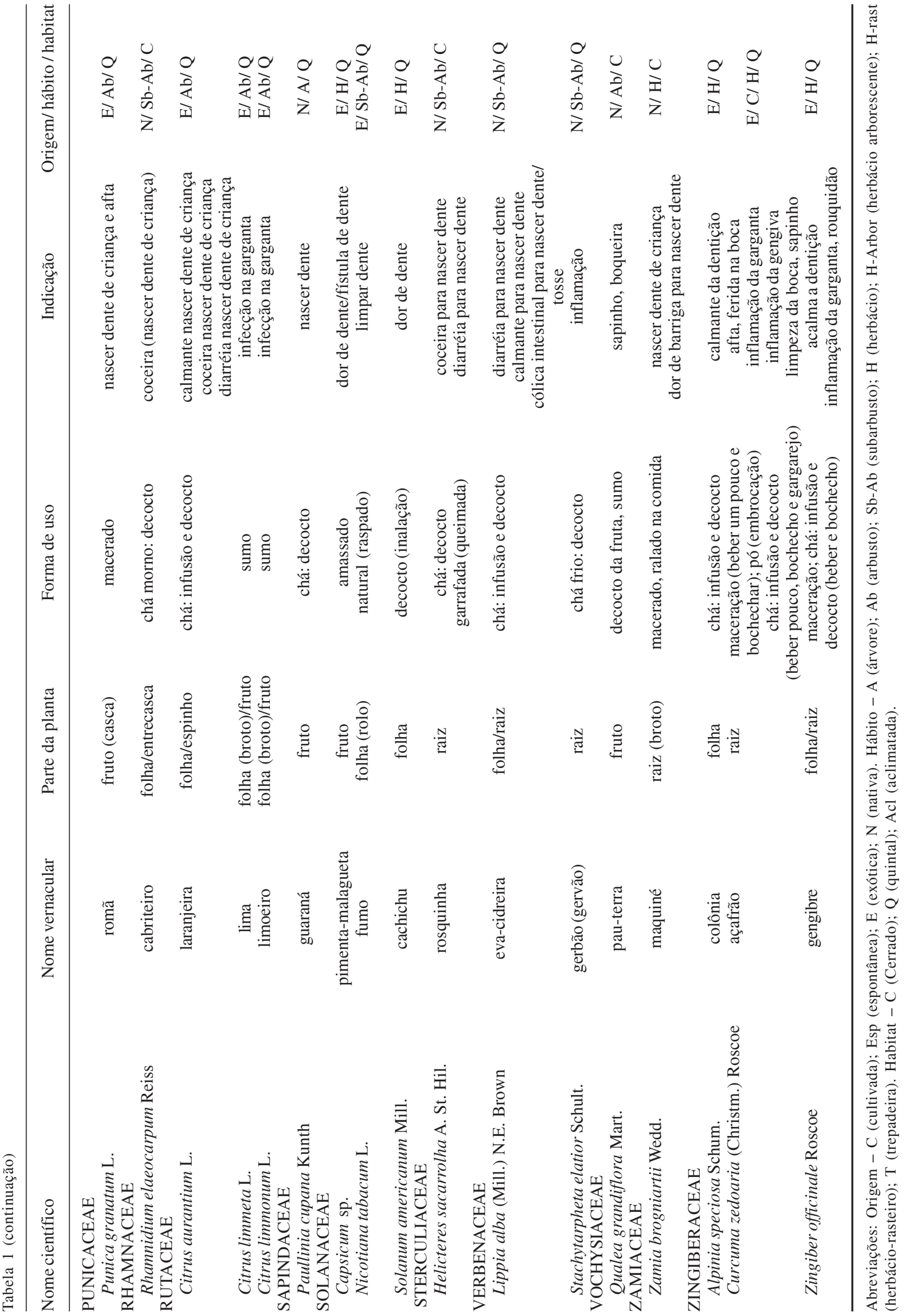


As plantas são utilizadas in natura ou após serem colocadas para secar à sombra por período de cinco a sete dias, permitindo o armazenamento por alguns meses, utilizando métodos empíricos aproximados das técnicas recomendadas por Macedo et al. (1998).

Observou-se que existem semelhanças e diferenças na maneira de uso, principalmente quando se refere ao modo de preparo da planta para ser utilizada. Alguns preferem preparar o chá da mesma planta por decocção, enquanto outros acreditam que por infusão ele se torna mais saboroso e eficaz. Uns usam mais as folhas do vegetal, enquanto outros acreditam que o efeito só é garantido utilizando a planta toda.

As informações obtidas, sobre as plantas medicinais usadas na comunidade do bairro Santa Cruz, como alternativa terapêutica em saúde bucal foram coletadas a partir do nome vernacular dado a cada espécie vegetal por seus usuários. São nomes comuns entre eles, havendo plantas conhecidas apenas por alguns informantes, como os que preparam garrafadas, as parteiras e os benzedeiros.

Observa-se que cada planta medicinal tem a sua característica de indicação terapêutica, podendo também, uma só planta ter várias indicações. Entre as 48 famílias botânicas citadas pelos informantes, prevaleceu Asteraceae (oito espécies, 9,2\%), seguida de Lamiaceae (seis espécies, 6,91\%) e Poaceae (quatro espécies, 4,60\%).

$\mathrm{O}$ uso terapêutico das plantas medicinais para a saúde bucal na comunidade apresentou grande diversidade, registrando-se a utilização de 87 espécies, dentro de 48 famílias, com um total de 47 indicações terapêuticas para as diversas afecções bucais que acometem os habitantes do bairro Santa Cruz.

A espécie com maior número de citações foi a camomila (Matricaria chamomilla L.), seguida da laranjeira (Citrus aurantium L.), poejo (Mentha pulegium L.) e marcela (Achyrocline satureoides (Lam.) DC.).

A espécie vegetal que obteve vegetal com maior diversidade de aplicação terapêutica para a saúde bucal foi o poejo (Mentha pulegium L.), seguida de goiabeira-branca (Psidium guajava L. var. pyrifera), açafrão (Crocus sativus L.), arnica-do-campo (Camarea ericoides St. Hil.), camomila (Matricaria chamomilla L.), mangava-brava (Lafoensia pacari A. St.-Hil.) e tanchagem (Plantago major L.).

Observou-se que existem plantas com indicação terapêutica específica para um tipo de problema na saúde bucal, por exemplo, o vinhático (Plathymenia reticulata Benth.), indicado na saúde bucal pelos informantes apenas para dor de dente, enquanto que a arnica-do-campo, arniquinha (Camarea ericoides St.-Hil.), é indicada para dor de dente, extração de dente, infecção, infecção de dente e machucadura.

Entre as 47 indicações terapêuticas para saúde bucal destacou-se dor de dente $(21,84 \%$ das espécies vegetais citadas), seguido de inflamação de dente $(16,09 \%)$, tosse, coceira na garganta $(14,94 \%)$, acalma a dentição (13,79\%), antiinflamatório $(12,64 \%)$, coceira na gengiva para dente nascer $(11,49 \%)$. As demais indicações possuem de uma a seis plantas citadas.

A sucupira-preta (Bowdichia virgilioides H.B.K.), indicada para dor de dente, também é citada por Macedo \& Pacheco (2001), no Município de Cuiabá, MT. O uso do gerbão (Stachytarpheta elattior Schult.), foi indicado para inflamação de dente, com dados semelhantes encontrados por Medeiros et al. (2004). A camomila (Matricaria chamomilla L.) foi a planta mais utilizada durante a fase de erupção dental. Relatos deste uso foram obtidos também por Silva (2001). Amann (1969) informa que as crianças neste período de erupção podem ter naturalmente febre e diarréia, e aconselha o uso de uma colher pequena de pó de guaraná (Paullinia cupana Kunth) por dia, para facilitar a dentição, e camomila (Matricaria chamomilla L.) para abrandar a diarréia.

Observou-se o uso da goiabeira (Psidium guajava L. var. pomifera) e do fumo (Nicotiana tabacum L.), para limpeza dos dentes e gengiva. Lorenzi \& Matos (2002) enfatizam que o fumo é empregado na medicina popular mesmo antes da chegada de Colombo às Américas.

Foi evidenciada a necessidade de recuperar esses conhecimentos que foram passados de geração a geração, apontando que, com o decorrer do tempo não foram perdidos e muito se ganhou em continuar lutando para se ajudar ao próximo. Esta prática e sabedoria dos recursos do uso das plantas medicinais resistiram aos anseios científicos de uma sociedade moderna, tendo como prioridade o bem estar da pessoa humana, ansiosa por atenção, carinho e solidariedade.

Constatou-se diversas espécies vegetais usadas pela comunidade com finalidade terapêutica em relação à manutenção e recuperação da saúde bucal: plantas nativas, encontradas no Cerrado e plantas exóticas, cultivadas em seus quintais.

As espécies de plantas medicinais nativas continuam sendo bastante usadas, apesar do número de espécies de plantas medicinais exóticas ser maior, em relação às plantas citadas. Observou-se que 
algumas espécies de plantas medicinais nativas não são mais facilmente encontradas nos arredores do bairro, impondo à comunidade buscá-las mais longe do local de moradia, como o para-tudo (Tabebuia aurea (Manso) Benth. \& Hook), arnica-da-serra (Brichelia brasiliensis (Spreng.) Robinson) e marcela (Achyrocline satureoides (Lam.) DC.).

A indicação terapêutica seguiu um padrão definido entre os residentes no bairro Santa Cruz, não havendo contradições quanto ao uso. A camomila (Matricaria chamomilla L.) foi a planta mais conhecida entre os informantes. A preferência da folha no preparo do medicamento é um costume que indica o cuidado com a preservação de recursos naturais da região. Quanto ao modo de preparo do medicamento caseiro, foram observados os cuidados de utilização da quantidade correta da planta e da obtenção de um medicamento de qualidade e sem contaminações, geralmente preparado pelo método da decocção.

\section{Referências bibliográficas}

ACIESP - Academia de Ciências do Estado de São Paulo. 1997. Glossário de Ecologia. $2^{a}$ ed. São Paulo, Publicação ACIESP n. 103.

Amann, C. 1969. Socorro aos doentes do sertão. Cuiabá, Escola Técnica Federal de Mato grosso.

Amorozo, M.C.M. 1996. A abordagem etnobotânica na pesquisa de plantas medicinais. Pp.47-68. In: L.C. Di Stasi (org.). Plantas medicinais: arte e ciência - Um guia de estudo interdisciplinar. São Paulo, Editora da Universidade Estadual Paulista.

Amorozo, M.C.M. 2002. O uso e diversidade de plantas medicinais em Santo Antônio do Leverger, MT, Brasil. Acta Botanica Brasilica. 16(2): 189-204.

Campanhola, C.; Luiz, A.J.B. \& Lucchiari Junior. 1997. O problema ambiental no Brasil: agricultura. Pp. 265-281. In: A.R. Romeiro; B.P. Reynon \& M.L.A. Leonardi (orgs.). Economia do meio ambiente: teoria, políticas e a gestão de espaços regionais. Campinas, UNICAMP/IE.

De-La-Cruz-Mota, M.G.F. \& Guarim Neto, G. 1996. O estudo de plantas medicinais por uma abordagem holística. Revista do Instituto de Saúde Coletiva 1: 9-17.

EMBRAPA 1994. Atlas do meio ambiente do Brasil. Brasília, Ed. Terra Viva.

Ferreira, J. C. V. 1997. Mato Grosso e seus municípios. Cuiabá, SEC.

Guarim Neto, G. 1987. Plantas utilizadas na medicina popular do estado de Mato Grosso. Brasília, $\mathrm{CNPq} / \mathrm{Assessoria}$ Editorial.

Lorenzi, H. \& Matos, F.J.A. 2002. Plantas medicinais no Brasil: nativas e exóticas cultivadas. São Paulo, Nova Odesa, Instituto Plantaurum.
Macedo, M.; Pinto, A.S. \& Somavilla, N. 1998. Guia do UFMT/ Herbário Central. Cuiabá, UFMT.

Macedo, M. \& Pacheco, I.B. 2001. Uso odontológico de plantas medicinais por idosos em Cuiabá, Mato Grosso, Brasil. Cadernos de Saúde - Cuiabá, UNIC - CPG 2: 63-73.

Macedo, M.; De Carvalho, J.M.K. \& Nogueira, F.L. 2002. Plantas medicinais e ornamentais da área do aproveitamento múltiplo em manso, Chapada dos Guimarães, Mato Grosso. Cuiabá, UFMT.

Matos, F.J.A. 1999. Plantas da medicina popular do nordeste: propriedades atribuídas e confirmadas. Fortaleza, UFC.

Medeiros, M.F.T.; Fonseca, V.S. \& Andreata, R.H.P. 2004. Plantas medicinais e seus usos pelos sitiantes da Reserva Rio das Pedras, Mangaratiba, RJ, Brasil. Acta Botanica Brasilica 18(2): 391-399.

Ming, L.C. 1996. Coleta de plantas medicinais. Pp.69-86. In: L.C. Di Stasi (org.). Plantas medicinais: arte e ciência - Um guia de estudo interdisciplinar. São Paulo, USP.

Neves, J.E.S. 1994. Chapada dos Guimarães: da descoberta aos dias atuais. Cuiabá, UFMT.

Pereira, G.; Aguiar, J.L.P.; Moreira, L. \& Bezerra, H.S. 1997. Área e população do Cerrado. Pesquisa Agropecuária Brasileira 32(7): 759-763.

Pinto, V.G. 1997. Epidemiologia das doenças bucais no Brasil. Pp. 27-42. In: L. Kriger (org.). Promoção de saúde bucal. ABOPREV. São Paulo, Artes Médicas.

Revilla, J. 2002. Cultivando a saúde em hortas caseiras e medicinais. Manaus, SEBRAE.

Ribeiro, J.F. \& Silva, J.C.S. 1996. Manutenção e recuperação da biodiversidade do bioma Cerrado: o uso de plantas nativas. Pp. 10-14. In: VIII Simpósio sobrer o Cerrado. Brasília. Anais... Brasília, EMBRAPA-CPAC.

Rodrigues, V.E.G. \& Carvalho, D.A. 2001. Plantas medicinais no domínio dos Cerrados. Lavras, UFLA.

Savastano, M.A.P.; Di Stasi, L.C. 1996. Folclore: conceito e metodologia. Pp.37-45. In: L.C. Di Stasi (org.). Plantas medicinais: arte e ciência - Um guia de estudo interdisciplinar. São Paulo, Editora da Universidade Estadual Paulista

Sano, S.M. \& Almeida, S.P. 1998. Cerrado: ambiente e flora. Planaltino, EMBRAPA-CPA.

Silva, R.C. 2001. Plantas medicinais na saúde bucal. Vitória, Artgraf.

Vieira, R.F. \& Martins, M.V.M. 1996. Estudos etnobotânicos de espécies medicinais de uso popular no Cerrado. Pp. 169-171. In: VIII Simpósio sobre o Cerrado. Brasília. Anais... Brasília, EMBRAPA-CPAC.

Viertler, R.B. 2002. Métodos antropológicos como ferramenta para estudo em etnobiologia e etnoecologia. Pp. 12-29. In: M.C.M. Amorozo; L.C. Ming \& S.M.P. Silva (orgs.). Métodos de coleta e análise de dados em etnobiologia, etnoecologia e disciplinas correlatas. Rio Claro, UNESP/CNPq.

Walter, L.R.F.; Ferelle, A. \& Issao, M. 1996. Odontologia para o bebê. São Paulo, Artes Médicas. 